\title{
PEDAGOGÍA MEDIEVAL HISPANA: TRANSMISIÓN DE SABERES EN EL BAJO CLERO
}

\author{
José María Soto Rábanos \\ CSIC. Madrid
}

\section{RESUMEN}

El saber clerical aparece como un bien instrumental, más que como un bien en sí, en la literatura destinada a los clérigos que cuidan de las iglesias. La adquisición de conocimientos en la Edad Media está justificada y condicionada por el puesto que cada cual ocupa en la Iglesia y en la sociedad. La expresión saber latín o ser gramático resume las exigencias para ser clérigo.

\begin{abstract}
Clerical learning appears to have been an instrumental good rather than a good in its own right, in literature that was designed for those clerics who would have charge of parish churches. The acquisition of knowledge in the Middle Ages was justified and conditioned by the post that each person occupied in the Church and in society. The expression to know Latin or to know grammar sums up the requirements for being a cleric.
\end{abstract}

\section{CONSIDERACIÓN DEL SABER CLERICAL}

Cabe preguntarse, aunque la formulación de tal interrogante pueda parecer sin sentido, si el saber se debe entender como un fin o como un instrumento. En verdad, si nos paramos a pensar en la compartimentación de saberes que hoy vige, queda de manifiesto que la adquisición de conocimientos tiene una finalidad hacia fuera del simple saber. Quien se forma en unos conocimientos, quien consagra bastantes años de su vida a recibir unos estudios con su título correspondiente, espera que esos estudios y ese título le sirvan de instrumento para llegar a ser un profesional, para instalarse como tal y asegurarse con ello un modo de vida.'

1 En la obra anónima Speculum peccatoris, confessoris et praedicatoris (conservada en el Ms. 37 de la Real Colegiata de San Isidoro de León), fol. 21r, se apunta a esta relación utilitaria entre ciencia y modo de vida, cuando se dice que quien gasta su patrimonio en la adquisición de saberes durante largo tiempo no se conforma con un beneficio de poca monta: «Non enim facile qui expendit patrimonium suum per magna tempora in studio laborando, vult reccipere benefficium curatum forte decem florenorum». 
En este sentido, el saber se considera un instrumento; pero, además de esta consideración pragmática, el saber tiene también una consideración finalista, de ser un bien en sí. Se entiende que la adquisición de conocimientos es indispensable para el desarrollo normal de la propia personalidad. Sencillamente, junto a esa visión práctica y utilitaria del saber, hay una conciencia generalizada de que el saber es un bien en sí mismo, algo propio del ser humano, algo necesario para la evolución del ser humano como tal, como animal racional.

Basta pensar en la vida escolar universitaria desde sus inicios, siglos XII-XIII. Los estudiantes, además de formar gremios (universitates studentium) para la defensa de sus intereses, consiguieron que el hecho de ser estudiante obtuviera carta de naturaleza; se estudiaba para y se estudiaba sin más, por saber. Nació así la figura del estudiante; y de esta figura deriva la figura del estudioso, del dedicado al estudio.

Sin prejuzgar la consideración del saber en otros ambientes y en otras literaturas dentro del medievo, analizando las referencias a los saberes de la literatura destinada a los curados, es decir, a los encargados de la cura de almas, cura que estaba, básicamente, en manos del clero bajo, ${ }^{2}$ llega uno a la conclusión de que en ella aparece, ante todo, la vertiente instrumental del saber; aparece la figura del estudiante para, no aparece la figura del estudioso.

La literatura pastoral considera el saber como un bien, pero no un bien en términos absolutos, o simples, un bien que halla justificación en sí mismo, sino como un bien relativo, un bien instrumental, un bien en cuanto sirve para un fin que es lo realmente bueno en sí. En esta literatura no interesa el saber como enriquecimiento personal; incluso, hay alusiones a que este aspecto de enriquecimiento de la persona mediante el saber podría caer dentro del pecado de soberbia. ${ }^{3}$

El saber contemplado en este tipo de literatura está en función del cargo, del puesto que cada cual ocupa en la Iglesia y en la sociedad; es un deber. Interesa, es obligado, que el clérigo, y especialmente el clérigo-cura, sepa; que sepa con suficiencia justamente aquello que tiene que saber para ejercer su función de tal, como interesa que el laico sepa justamente aquello que le es preciso para ser cristiano.

En este sentido se debe interpretar, a mi entender, lo que al respecto afirma Gonzalo de Alba, teólogo dominico, catedrático de prima de teología en la universidad salmantina, obispo de Badajoz (1407-1408) y de Salamanca (1408-1412), en el libro sinodal promulgado en el sínodo salmantino de $1410^{+}$(c. 10 de la versión original en latín y c. 6 de la versión

2 Los autores pastoralistas dan por hecho que la cura de almas está en manos del clero bajo, bajo en ciencia y en poder social y económico.

3 Martín Pérez, en su voluminosa obra, aún inédita, Libro de las confesiones, parte $2{ }^{\mathrm{a}}$. cap. XLI, fol. 59r (Ms. 21 de la Real Colegiata de San Isidoro de León), después de señalar lo que el clérigo debe saber, precisa que no debe profundizar en las ciencias menores más allá de lo necesario para su oficio, para aparentar; esto sería pecado de soberbia: «Et non se deue detener en las çiençias menores assy commo gramatica rretorica las naturas [...] para parescer, ca esto es soberuia».

4 Este libro sinodal lo presenta como propio el dominico Lope de Barrientos, obispo de Segovia (14381441), de Ávila (1441-1445) y de Cuenca (1445-1469), en los sínodos de Turégano (1440) y Cuenca (1446). Cf. A. García y García, F. Cantelar Rodríguez y B. Alonso Rodríguez, «El Liber synodalis salmantino de 1410 », Revista Española de Derecho Canónico, 41 (1985), 347-364; publicado asimismo en A. García y García, Iglesia, Sociedad y Derecho, 2 (Salamanca, 1987) 433-450. 
en romance), donde señala que en la Iglesia hay tres grados o niveles de saberes, conforme a las tres categorías en las que se distribuyen sus miembros: uno, para los altos (el papa y los obispos), a quienes compete un conocimiento amplio y explícito de la fe en toda su profundidad, para poder defenderla contra los herejes y para el adoctrinamiento de los inclinados a la conversión; otro, para los medianos (los simples clérigos curados y los maestros, al estilo de los predicadores y doctores), a quienes compete también un conocimiento abierto y explícito, pero sólo hasta cierta medida, en lo que conviene a su oficio, es decir: conocimiento de los artículos de la fe en cuanto a la substancia y de lo que pertenece a la cura de almas, que se concreta en la administración de los sacramentos y en la enseñanza-predicación de la doctrina cristiana; y un tercer grado para los bajos (los laicos), a los que no compete un conocimiento abierto y explícito, solamente saber lo que les enseñen los clérigos y lo que cualquiera puede aprender de forma consuetudinaria. ${ }^{5}$

A primera vista, no parece coherente incluir a los que se dedican a enseñar, a los maestros, al estilo de predicadores y doctores, en esta categoría intermedia, junto a los clérigos curados en general. Cierto es que, por lo que respecta a maestros y predicadores, la equiparación con los curados tiene, en teoría al menos, un sentido lógico, ya que a los curados corresponde, efectivamente, enseñar y predicar; pero, en ningún caso se les pide que sean doctores. Quizá se deba entender aquí el término de doctores, no en su sentido propio, que se aplicaría a quienes habían obtenido un grado alto (no ya mediano) de conocimientos, sino en un sentido más genérico, que cabría aplicar a quienes eran suficientemente peritos como para cumplir una misión de enseñanza y predicación de la fe, que se considera por debajo de la misión del papa y de los obispos.

Clemente Sánchez de Vercial, en su obra Sacramental, acabada de escribir en 1423, recoge asimismo estos tres grados de saberes en la Iglesia; pero, en el segundo nivel sólo cita a los clérigos curados, sin ocuparse en el caso de otros maestros, predicadores o doctores, y evitando así posibles malentendidos. ${ }^{6}$

5 Synodicon hispanum IV: Ciudad Rodrigo, Salamanca y Zamora, edición crítica dirigida por A. García y García (BAC, Madrid, 1987), 80-81 (versión latina): «Vnde triplex est gradus in Ecclesia [...] Supremi, ut papa et episcopi, tenentur scire istos articulos explicite et causam et rationem reddere, et non solum hoc, set etiam contra hereticos defendère, et dispositiones ad credendum declarare et persuadere [...] Medii uero in Ecclesia sunt curati simplices et qui ex officio habent alios docere, ut predicatores et doctores. Et isti tenentur explicite scire quidquid pertinet ad officium suum, scilicet, ad articulos quantum ad substantiam eorum, et quidquid pertinet ad administrationem sacramentorum [...] Infimi et inferiores, ut populus communis, non tenentur explicite scire nisi quantum traditum est eis ex doctrina maiorum et ritu Ecclesie, qui neminem latet, nisi ob culpam suam ab hoc impediatur».

6 Fol. XIv: «Todo christiano deue saber los articulos dela fe, commo quier que en diuersas maneras [...] $\mathrm{Ca}$ los legos los deuen saber breuemente [...] E los clerigos que han curas de animas mas clara e abiertamente segund se contiene enel credo in vnum deum. E los perlados mayores non solamente los deuen saber bien declarados mas aun deuen dar razon dellos quando les fuere preguntado». Poco más adelante, en fol. XIIv, insiste en la idea: «Estos catorze articulos asi breuemente dichos se deuen saber por todo christiano clerigo 0 lego. Pero mas clara e mas largamente se deuen saber por los clerigos que han cura de animas e por los perlados que han iurisdiciones». 
Es cierto que lo señalado en el libro sinodal de Gonzalo de Alba y en el Sacramental de Clemente Sánchez se puede entender como un límite a quo o un punto de partida, como el tope mínimo, aquello que es obligatorio; directamente, no se señala un tope máximo, un límite ad quem, no se prohíbe saber más. Pero es cierto igualmente que, de forma indirecta, se trazan límites de conocimientos también por arriba, al dejar bien sentado lo que corresponde a cada nivel. Además, en cuanto a los laicos, se toman medidas para que no crezcan, para que no lleguen a más altos conocimientos. En la constitución citada del libro sinodal de Gonzalo de Alba se indica que los fieles laicos no se deben entrometer en demandar razón de las cosas de la fe, ni deben entrar a disputar sobre ellas, ni deben hacer caso a lo que les pueda parecer sobre ellas, según su propio entender; antes bien, se limitarán a creer con firmeza lo que la Iglesia propone. ${ }^{?}$

\section{DINAMISMO Y ESTATICISMO DE LOS CONOCIMIENTOS}

Se ha señalado que el saber hasta, aproximadamente, el siglo XIII, ${ }^{8}$ hasta la aparición del arte gótico como primera expresión plástica de una nueva visión del mundo y del fenómeno cultural, se concibe como algo estático, como parte de una realidad que está ahí, en lo creado, con su ser y sus límites marcados y que simplemente alcanzamos en mayor o menor grado unos y otros. A partir de entonces, sin embargo, se empieza a entender el saber como una fuerza dinámica, como una potencia creadora; unos conocimientos dan lugar a otros; hay una generación, una creación de saberes. La capacidad intelectiva del ser humano no se tiene que conformar simplemente en ofrecer razones o explicaciones de los hechos, de lo existencial, sino que puede entrar a teorizar, y entra de hecho, sobre las esencias de las cosas, de la realidad toda y del propio ser humano.?

Si, de una parte, la filosofía se entiende como ancilla, es decir, al servicio de la teología; de otra, nos encontramos con que las cosas de la fe, las creencias, desde la misma existencia de «dios», se intenta explicarlas a través del razonamiento, con lo que se está dando ya un sentido primario al razonamiento, a la inteligencia, al saber razonado frente al saber aceptado. Y si esto es así en el ámbito de la fe, lo es también, y se podría decir a fortiori o con mayor razón, en el ámbito de las ciencias humanas y de las realidades materiales.

7 Synodicon hispanum IV. 81: «Frequenter ergo moneant sacerdotes laicos ne circa Trinitatem uel articulos fidei seu sacramenta Ecclesie rationem querant, quomodo uel quare ita sit, et inhibeant eis ne de talibus disputent, set sine omni dubitatione credant firmiter omnia quecumque catholica fides asserit et sancta Romana Ecclesia tenet, quamuis in speciali non possint habere intellectum, magis testibus fidei [...] credendo quam suis sensibus».

8 En realidad, hoy se reconoce que el renacimiento cultural europeo se gesta durante el siglo XII, acelerándose en su segunda mitad; y los frutos de este renacimiento maduran y se recogen mayormente en el siglo XIII.

9 Sobre la concepción del saber en el medievo, cf. J. A. Maravall, Estudios de Historia del Pensamiento español, I: Edad Media (Madrid, 1983), 203-254. 
La pregunta es si este cambio se advierte en la literatura pastoral.

En los sínodos no se advierte un cambio decisivo y claro al respecto. Se puede atisbar, en todo caso, un cierto cambio, al menos formal, apenas perceptible de un sínodo a otro, pero que me parece incontestable en una visión comparativa global entre los sínodos de los siglos XIII, XIV y XV. Entiendo que se trata de un cambio casi obligado, actuado por la inercia misma del dinamismo propio de otros ámbitos literarios, científicos y sociales; un cambio a remolque del que se está operando entre la elite de la sociedad.

Por otra parte, me parece que este estaticismo básico, esta falta de dinamismo que se observa en la literatura sinodal, es algo intencionado, algo buscado por los autores de los sínodos; y, en última instancia, por las autoridades eclesiásticas. Dos razones encuentro para ello; una atiende al contenido y otra a los destinatarios de los sínodos.

En cuanto al contenido, los sínodos transmiten lo elemental de la fe, los dogmas, el conjunto de creencias, de verdades de fe, que, por su propia naturaleza, se consideran invariables, sólo enriquecibles a través de un desarrolo puramente formal, mediante la explanatio (exposición) de los entendidos, de los doctores; y las obligaciones cristianas, que la autoridad eclesiástica se encarga de establecer. En pocas palabras, el contenido cubre lo que el fiel debe creer, lo que debe hacer y lo que debe evitar, fundamentando todo en leyes divinas, leyes inmutables substancialmente.

En cuanto al destinatario, los sínodos van dirigidos a la diócesis en general para aplicar en ella ordenanzas eclesiales de mayor rango: normas de concilios provinciales, nacionales, legatinos, ecuménicos; es decir, para aplicar y adecuar a cada diócesis las disposiciones generales de la Iglesia, su corpus iuris. Los destinatarios concretos de estas normas son los clérigos diocesanos y, en parte, a través de los clérigos, los laicos. Es sabido que una buena parte de los clérigos curados (en contradicción con los saberes que teóricamente se les exigía) y la mayoría de los laicos eran iletrados o casi. Por ello, se les entrega lo que deben transmitir y lo que deben saber en fórmulas invariables, además de breves, que puedan memorizar, aprender de coro, y a las que puedan aferrarse sin exponerse a discusiones y posibles errores. ${ }^{10}$

No obstante, se observan algunos cambios que afectan a aspectos puramente formales. Destaco los dos que me parecen más importantes:

a) la atención al fiel laico se hace progresivamente más clara e intensa, en la labor del clérigo cura se destaca más y más la faceta de atención al fiel, la vertiente ad hominem;

10 Los sínodos y libros sinodales (excepción hecha de los de la provincia tarraconense, en los que apenas hay referencias al problema), así como los manuales para uso de párrocos, aluden con frecuencia a la ignorancia de los clérigos y en ella fundamentan la ignorancia religiosa de los laicos.

Con respecto a estas denuncias de ignorancia clerical, como a otras denuncias que se hallan en los sínodos, hay que tener en cuenta que los sínodos constituyen un género literario que se caracteriza por exagerar lo negativo del comportamiento moral de la sociedad y, principalmente, del estamento eclesiástico. Por otra parte, son reiterativos, en cuanto usan y abusan de fórmulas estereotipadas, heredadas; $y$, a veces, no queda claro si reflejan una realidad concreta. 
b) en parte, como consecuencia de esta mayor atención al fiel y, en parte, como concesión obligada a la realidad de la lengua hablada, vulgar, que se imponía sobre el latín (limitado a la gente culta), los sínodos utilizarán de forma progresiva la lengua romance.

El uso del romance en los sínodos no es una cuestión baladí, dado que con frecuencia contienen instrucciones de la doctrina cristiana, en cuya expresión literal es obligado precisar al máximo. Se observa un cuidado extremo en la inamovilidad de la materia a enseñar; con el cambio de lengua, del latín al romance, se corre el peligro siempre grave de no expresar bien la verdad. En este sentido, Pablo de Santa María, obispo de Burgos, es un ejemplo ilustrativo. En el sínodo de 1418 se dedicó en exclusiva a corregir el articulado de la fe promulgado en romance por su antecesor, Juan Cabeza de Vaca, porque, en su opinión, contenía impropiedades, equivocaciones y lagunas. Sencillamente, no se fiaba del todo de la lengua romance. ${ }^{11}$

En los tratados o manuales breves no hay tampoco lugar a observar algún cambio en el sentido indicado, ya que sus autores se limitan a resumir lo esencial de la doctrina cristiana, sin entrar en cuestiones discutidas o discutibles. En los tratados más amplios, al estilo de la Summa de casibus poenitentiae de Raimundo de Peñafort, o del Sacramental de Clemente Sánchez de Vercial, o del Speculum peccatoris, confessoris et praedicatoris, sí hay referencias a cuestiones discutidas y a soluciones razonadas, de modo que en los casos de duda la solución práctica se deja a la decisión personal y racional del clérigo ante quien se plantee debidamente el problema. Entiendo que ello se debe a que los autores de este tipo de obras buscan, en verdad, algo más que ser útiles al clero bajo, aunque en sus exposiciones de motivos sólo indiquen su «humilde» papel de ayuda al clérigo curado; buscan, además, expresar sus opiniones y poner de manifiesto sus conocimientos, su competencia, su puesta al día en la materia.

\section{SELECCIÓN DE CONTENIDOS CULTURALES: CULTURA RELIGIOSA}

Los sínodos y los tratados de teología pastoral se limitan directamente a los saberes religiosos o, mejor, a los saberes que dicen relación a lo religioso. Puede parecer paradójico, aunque tiene su lógica, que, siendo puramente religiosa la motivación de esta literatura, su contenido sea más estrictamente religioso cuanto menor es la vinculación de las personas relacionadas al estamento eclesiástico.

11 Título De summa trinitate (edición de N. López Martínez, «Sínodos burgaleses del siglo XV», Burgense, 7 [1966]: 305-306): «E por quanto en las constituciones del obispo don Juan Cabeça de Vaca [...] Por ende, acordamos de notar las cosas en que los dichos artículos son de corregir [...] e después poner los artículos en la forma en que se deuen poner, en el romance más seguro [...] e donde no falláremos tal romance, poniendo el latín que es común usado de los doctores de la santa yglesia». 
A los clérigos se les recuerda que deben ser suficientemente peritos en tres aspectos: conocimiento de las Escrituras y de la disciplina eclesiástica, conocimiento de las ciencias profanas y conocimiento de los asuntos seculares. ${ }^{12}$

Con relación a los simples fieles, se atiende exclusivamente a que conozcan de coro y formulariamente la doctrina cristiana y a que cumplan en todo sus deberes religiosos; cuando se citan profesiones y oficios civiles, públicos y privados, es sólo para señalar la normativa eclesiástica que debe guiar a los fieles en el desempeño de los mismos. ${ }^{13}$

Aunque se condena la ignorancia en general como un mal, no hay expresiones de estímulo, de aliento, para que los cristianos laicos cultiven el aprendizaje de alguna profesión o ciencia; o para que aprendan a leer, simplemente. En el sínodo de Braga de 1477, c. 7, se alude ocasionalmente al aprendizaje de la lectura, tratando de vincularlo a la familia, más que a la Iglesia. ${ }^{14}$ No preocupa, directamente, si adquieren o no otro tipo de cultura 0 de desarrollo de la personalidad, aunque se da por hecho que existe una enseñanza, formación o aprendizaje, cuando menos, tradicional (de padres a hijos), tanto en las profesiones liberales como en las tareas o labores serviles, que salen a la luz por su repercusión en los deberes cristianos, como el pago de los diezmos o el comportamiento moral en el quehacer diario, en la profesión, de cada cual..$^{15}$

En definitiva, la literatura pastoral recoge ante todo la doctrina de fe de la Iglesia y la normativa de conducta de los creyentes, en especial de los clérigos, y, en segundo lugar, de los laicos. Se refiere, por ello, principalmente, a dos tipos de conocimientos: teológicos y jurídicos. ${ }^{16}$

12 Esta formulación sobre el triple saber clerical aparece de forma reiterativa en los tratados para curados; los sínodos se fijan más en el conocimiento de la gramática (del latín) y de la doctrina cristiana.

13 Martín Pérez, por ejemplo, dedica la segunda parte de su Libro de las confesiones a los pecados según los estados y las profesiones de las personas. Con este motivo, ofrece una relación interesante de oficios y profesiones implantados en la sociedad de su tiempo, pero sin otro ánimo que el de señalar la conducta moral a seguir por los oficiales y profesionales.

14 Synodicon hispanum II. 85: «E porque achamos que se faz grande destruiçom nos livros das egrejas e moesteiros por causa dos moços que aprendem per elles, defendemos a todollos beneficiados assy da nossa see como de quaaesquer egrejas e moesteiros que o nom consentam, salvo aquelles moços que já souberem leer e cantar. Mas os outros que esto nom souberem e quiserem aprender, seja o cuidado de seus padres e madres e daquelles com que viverem que lhes busquem os livros per que aprendam e nom destruam os das egrejas e moesteiros. Porém despois que souberem, podem leer e cantar no coro pellos dictos livros da egreja».

15 El pago de los diezmos es una constante en los sínodos, mientras que la conducta moral profesional se explicita más en los tratados doctrinales.

16 Se reflejan, básicamente, las normas jurídico-canónicas y, ocasionalmente, algunas civiles; por ejemplo, en el sínodo de Salamanca de 1497, c. 37, 38 y 48 (Synodicon hispanum VI. 394-396 y 414), se remite a disposiciones de Juan I, de Alfonso IX, de Alfonso X, de Enrique III; y en el de Ávila de 1481, c. 2.5.2, 4.2.19, 9.7 (Synodicon hispanum VI. 119, 177-179, 215-216), a disposiciones de Juan I y de Enrique III. 


\section{EL DEBER DE SABER. EXIGENCIA MÍNIMA DE SABERES: SER GRAMÁTICO, O SEA, SABER LATÍN, EJE DE LA CULTURA CLERICAL}

\section{A) Visión de los tratadistas}

Los autores de manuales de teología pastoral parten de la insuficiencia de conocimientos de los clérigos curados, pero no se detienen en muchas consideraciones teóricas sobre lo que deben aprender y cómo pueden aprenderlo. La ciencia clerical no es la temática propia de estos escritos, aunque esté en su origen, y no cabe esperar que traten de ella con detenimiento. Se limitan a señalar el ideal, incluido por San Pablo en la virtud de la prudencia: ${ }^{17}$ un ideal que exige ser perito en tres vertientes del saber: conocimiento de las Escrituras y de la disciplina eclesiástica, conocimiento de las ciencias profanas, conocimiento de los asuntos seculares. ${ }^{18}$

En realidad, el texto paulino hace referencia directa a sólo el obispo, pero puede y debe aplicarse a todos los clérigos. ${ }^{19}$

Por otra parte, los autores no especifican las exigencias de ciencia conforme a las diversas clases de clérigos, dado que se dirigen exclusivamente a los que tienen ya o están dispuestos a tener un beneficio con cura de almas; no tienen en cuenta a los clérigos por razón de sus diversas categorías, sino sólo en razón de su vinculación con la tarea pastoral. Se observa, aunque no siempre se precise con claridad, una exigencia de saber común a todos los clérigos, que se concreta en el conocimiento de la teología y, en última instancia, de la gramática. A ello habría que añadir el conocimiento del oficio; en el caso, el oficio de cura, de clérigo con cura de almas.

La responsabilidad de la enseñanza a los clérigos curados recae en los obispos, quienes por sí mismos o por maestros ad hoc deben instruir e informar a sus ordenandos en los oficios divinos y en la administración de los sacramentos. ${ }^{20}$ De esta base parten todos los tratadistas.

17 I Tim. 3.2: «Oportet ergo episcopum [...] esse [...] prudentem».

18 Raimundo de Peñafort, Summa, lib. 3 tit. 5 (ed. Roma, 1601, p. 268): «Oportet et ordinandum esse prudentem: debet enim habere triplicem peritiam, videlicet sacrae scripturae [...] secularium litterarum... secularium negotiorum».

19 Raimundo de Peñafort (Summa, lib. 3 tit. 1 [p.258]) recoge así esta interpretación tradicional: «Licet autem apostolus videatur regulam in episcopo posuisse, tamen, vt ait Augustinus, et etiam Ambrosius, inducens ad probandum auctoritatem Niceni Concilij, extendenda est ad alios ordinandos». Del mismo modo, pero en romance, Clemente Sánchez de Vercial (Sacramental, fol. CLXIr): «E commo quier que el apostol puso estas condiciones alos obispos, pero deuen se estender a todos los que se ordenan segund dize sant Ambrosio e sant Agustin».

20 Concilio lateranense IV, c. 27 (constitución incluida en el Liber Extra [Decretales] de Gregorio IX 1.14.14): «Cum sit ars artium regimen animarum, districte praecipimus, ut episcopi promovendos in sacerdotes diligenter instruant et informent vel per se ipsos vel per alios viros idoneos super divinis officiis et ecclesiasticis sacramentis, qualiter ea rite valeant celebrare» (edición de Alberigo et alii, Conciliorum Oecumenicorum Decreta [COD], Bologna 3, 1973, 248). 
Al hilo de esta responsabilidad, Raimundo de Peñafort ( $c a .1185-1275)$, que fue el copilador de las Decretales de Gregorio IX (promulgadas el año 1234), recuerda lo establecido por los concilios lateranenses III (1179) y IV (1215) $)^{21}$ sobre la dotación de maestros de teología en las iglesias metropolitanas para instruir a los sacerdotes y demás clérigos en la teología y en todo lo referente a la cura de almas, ${ }^{22}$ y de maestros de artes liberales (de gramática) en las iglesias catedrales y en otras iglesias importantes para la enseñanza del trivium.

Raimundo de Peñafort excluye el quadrivium del programa teórico oficial porque sus materias, aunque respondan a la verdad, no llevan a la devoción, a la piedad. ${ }^{23}$

Estas escuelas diocesanas, en su mayoría al menos, reducen de hecho su enseñanza a la gramática y al canto llano (música religiosa), por lo que cabe deducir de las referencias que hacen a ellas los tratadistas y los sínodos. El mismo Raimundo de Peñafort se conforma con que en estas escuelas se enseñe la gramática, por ser ésta la materia exigida pricipalmente por las normas canónicas. ${ }^{24}$

La pericia en los negocios seculares no está unida a ningún tipo especial, concreto, de enseñanza escolar, de instrucción reglada; no está adscrita a un maestro, a una escuela. Infiero de ello que debe entenderse como una cualidad que el clérigo va adquiriendo, o puede ir adquiriendo, junto con la formación en teología y en artes y con la propia evolución

21 c. 18 y 11 , respectivamente (COD, 220 y 240 ).

22 Summa, lib. 3 tit. 5, p. 268: «Et propter hoc statutum est. vt in Ecclesijs metropolitanis teneantur doctores theologiae». Ibíb., lib. 1 tit. 3 \$ 1, p. 30: «Item quod Metropolitana Ecclesia Theologum nihilominus habeat, qui Sacerdotes, et alios in sacra pagina doceat; et in ijs praesertim informet, quae ad curam animarum spectare noscuntur».

23 Summa, lib. 3 tit. 5. p. 268: «Seculares scientias debet scire ad eruditionem, vt possit discernere verum a falso, et per eas habere aditum ad scientias pietatis; non autem ad voluptatem, vel delectationem [...] ideo etiam statutum est, vt teneantur magistri liberalium artium [...] sed de triuialibus tantum [...] Secus in quadriuialibus [...] quia illae, licet in se contineant veritatem, non tamen ducunt ad pietatem».

Esta postura negativa o, al menos, restrictiva de Raimundo de Peñafort sobre las disciplinas del quadrivium extraña no poco en un personaje de su categoría intelectual y conocido promotor de los estudios en su orden religiosa (Orden dè Predicadores) y en el ámbito de la Iglesia en general, pero se sitúa dentro del sentir canónico-eclesial de su tiempo.

24 Summa, lib. 1 tit. 3 \$ 1. p. 30: «Nota ergo, quod statutum fuit quondam ab Eugenio Papa (1145-1153), postea ab Alexandro in Concilio Lateranensi [Letrán III, 1179], deinde ab Innocentio in Concilio Generali [Letrán IV, 1215], quod singulae Ecclesiae Cathedrales tenerent singulos Magistros liberalium artium, ad minus grammaticae».

Guillermo de Redon, contemporáneo de Raimundo y glosador de la Summa, anota que las disposiciones relativas a los maestros de teología y de artes liberales se observaban mal: «Hoc statutum, et caetera statuta de duobus magistris male obseruantur» (ibíb., glosa al margen izquierdo, letra b).

La gramática, a la que se hace referencia constante, aunque no sea propiamente una disciplina teológica, se entiende referida a la teología, en cuanto medio necesario para asimilar de alguna manera las verdades de la fe. La gramática es el latín, la lengua culta y cultual, el vehículo de expresión de la teología, de la filosofía y del derecho. 
de su persônalidad, como una capacitación personal, más que como un saber adquirido de la enseñanza específica de un maestro.

Las exigencias anotadas por Raimundo de Peñafort y sacadas de la normativa canónica son, con pocas variantes, las mismas que recogen los tratados de pastoral posteriores, hasta la segunda mitad del siglo XV.

La Primera Partida de Alfonso X el Sabio (1252-1284) ofrece un dato importante que no he visto explicitado en otros autores: el aprendizaje dẹ la música para saber cantar en la iglesia. El rechazo o, mejor, la no inclusión expresa de la música entre las disciplinas clericales por parte de los autores pastoralistas, se debe, a mi entender, a su pertenencia al quadrivium, en el que se incluyen materias que no conducen a la piedad. Sin embargo, con referencia específica al canto llano (música religiosa), se puede interpretar que estos tratadistas lo consideran incluido implícitamente en los estudios de gramática. En la normativa sinodal, la lectura, el canto y la gramática van juntos, como exigencia conjunta, de modo que, aunque, a veces, se hable sólo de gramática, de la obligación de ser gramáticos, se entiende que la referencia vale también para la lectura, por supuesto, así como para el canto.

En el Libro de las confesiones de Martín Pérez, escrito en torno a los años 1316-1320, se resalta la mera instrumentalidad de los saberes no teológicos para los clérigos, sin aludir a la diferenciación entre el trivium y el quadrivium; estos saberes no teológicos constituyen ciencias menores en las que el clérigo no se debe detener más allá de lo que le puedan ser útiles en el desempeño de su oficio. El mismo saber teológico aparece limitado a la exigencia del oficio en el clérigo curado. ${ }^{25}$

En el Manipulus curatorum de Guido de Monte Roterio (obra escrita en Teruel el año 1333) se insiste en la enseñanza de la gramática, entre las ciencias del trivium, por ser la más útil de las tres. Al igual que Raimundo de Peñafort, a quien sigue de cerca, las ciencias del quadrivium nada dicen a la piedad. ${ }^{26}$

Guido diferencia, teóricamente, lo que se exige a todos los clérigos, nociones de teología y gramática, como queda anotado, y lo que, además, corresponde a los sacerdotes, en especial a los que tienen cura de almas, por razón de su oficio. Como sacerdotes simples, sin cura de almas, deben ser gramáticos, para celebrar bien la misa, entendiendo, cuando menos ad litteram, lo que en ella se contiene. O sea, que no añade nada nuevo a lo exigido al clérigo en general; simplemente, precisa la utilidad del saber gramátical para el sacerdote, de modo que si cualquier clérigo debe ser gramático, con mejor razón deberá serlo el sacedote para celebrar dignamente la misa. Los curados deben tener conocimiento de otras

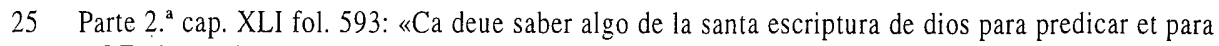
enseñar [...] Et deue saber gramatica para leer sin falso en la eglesia [...] Et non se deue detener en las çiençias menores asy commo gramatica rretorica las naturas $[\ldots] »$.

26 Pars 1. ${ }^{\text {a }}$ tractatus 5us caput $5^{\text {us }}$ (BEscorial, incunable 61-VII-19 n. 2 fol. 34va-vb): «Vnde ordinandus [...] Debet habere etiam peritiam scripturarum secularium [...] et intelligo de scientiis triuialibus [...] quia quadriuiales scientie [...] parum aut nihil faciunt ad scientias pietatis». 
tres materias, amén de la gramática: de los sacramentos, su número, materia y forma de cada uno, y modo de administrarlos; de los pecados, saber discernirlos y la penitencia a imponer; de los artículos y demás rudimentos de la fe, para enseñarla. Hasta aquí, la teoría, el desideratum; a la hora de la verdad, de la exigencia práctica, se conforma con que sean buenos gramáticos, dando por supuesto que los curas neófitos saben poco. Para que aprendan y puedan ejercer correctamente el oficio disponen de obras como la suya, que deben tener a mano. ${ }^{27}$

En la obra Speculum peccatoris, confessoris et praedicatoris de un autor español anónimo del siglo XV (escrita ca. 1431-1435), se hace caso omiso de la división entre las ciencias mayores y menores, sagradas y profanas, el trivium y el quadrivium; importa simplemente que el clérigo con cura de almas, o que va a recibir un beneficio curado, esté bien preparado en los conocimientos que interesan para tan delicada tarea como es la cura de almas. Fija como ideal que no se acepte ni se conceda la cura de almas sin tener estudios de teología y de derecho canónico y civil, de una duración mínima de dos a tres años; pero, en última instancia, se conforma con menos: que el candidato tenga conocimiento de la gramática. ${ }^{28}$

Por lo demás, el autor de la obra insiste repetidamente en recriminar la negligencia de los obispos a la hora de conceder los beneficios curados; se guían por los afectos, no por juicios de razón. ${ }^{29}$

En conclusión, los autores de los manuales para uso de los clérigos con cura de almas coinciden en una exigencia mínima de ciencia: tales clérigos deben ser gramáticos.

27 Prologus, fol. Iva-vb: «Quamobrem quicumque uult suum officium bene exequi debet scire que ad officium suum spectant. Officium autem sacerdotum maxime curatorum consistit in quatuor secundum quattuor ethimologias istius nominis [...] sacerdotes sunt missarum celebratores [...] sacrorum ministratores [...] confessionum auditores [...] plebis doctores [...] Ergo propter primum debent habere tamtum de scientia quod sciant recte et distincte legere et congrue pronunciare et accentuare: et ad minus grammaticaliter intelligere ea que in misse officio continetur. Propter secundum debent habere tamtum de scientia quod sciant numerum sacramentorum et que sit debita forma et debita materia cuiuslibet sacramenti et modum ea debite ministrandi, potissime et sacramentis que ad eos spectant. Propter tertium debent habere tamtum de scientia quod sciant discernere inter lepram et lepram, id est, inter peccatum et peccatum et penitentias imponere salutares. Propter quartum debent habere tamtum de scientia quod sciant ad minus populum in articulis fidei et aliis rudimentis fidei informare. Omisso autem primo quia illud spectat ad grammaticam [...] de tribus aliis in hoc libello est agendum: quem libellum uolui manipulum curatorum uocari ex eo quod sacerdotes potissime curati debent istum libellum portare in manibus: ut uideant ea que circa officium sunt agenda».

Sobre el poco saber de los curas neófitos, se pronuncia en varias ocasiones, precisando que a ellos, a su orientación en la práctica de la cura de almas, va dedicado su Manipulus. Así, por ejemplo, en los folios 1rb, $1 \mathrm{va}, 36 \mathrm{va}, 45 \mathrm{va}, 84 \mathrm{vb}$.

28 Fol.VIv: «Cum ergo secundum beatum Gregorium ars artium sit regimen animarum, qua temeritate qui, non dico per duos vel tres annos, set numquam studuerunt in medicina animarum, hoc est, in theologia, iure canonico et ciuili, ymmo nec scientes adhuc bene grammaticam, audent recipere curas animarum».

29 Fol. VIr: «carnalitatis sequentes affectum non iudicium rationis, beneficia curata suis nepotibus et familiaribus conferunt simplicibus et ydiotis, qui nesciunt adhuc curare seipsos».

De forma parecida en folios $2 \mathrm{v}, 3 \mathrm{v}, 20 \mathrm{v}, 61 \mathrm{v}, 109 \mathrm{r}$. 


\section{B) Normativa sinodal}

Antes de analizar las disposiciones sinodales, creo oportuno advertir que el tema de la ciencia clerical no se cuenta entre los preferidos por los sínodos que han llegado hasta nosotros. La importancia prioritaria que los sínodos conceden al tema no se corresponde con el tratamiento cualitativo y cuantitativo, por lo general deficitario, que esos mismos sínodos nos ofrecen; en bastantes de ellos no se halla siquiera una referencia. ¿Quizá porque esta cuestión no era problemática? No parece una razón convincente; al contrario, los datos de que disponemos indican que el problema existía y que era bastante grave, en líneas generales. Los mismos sínodos, cuando dictan normas sobre el particular, testimonian, a veces con fórmulas repetitivas de un valor incierto, pero a veces con detalles bien circunstanciados, de un indudable valor histórico, que la falta de ciencia en los clérigos, y sobre todo en los curados, constituía un problema de suma importancia; y, desde luego, se puede afirmar que cuando el problema es asumido, se presenta como de la máxima gravedad. ${ }^{30}$

La normativa sinodal propone como exigencia primera mínima, y suficiente en principio, para ser clérigo curado, saber leer, cantar (canto llano, música religiosa) y gramática. Todo ello se resume con frecuencia en la expresión: saber hablar en latín. ${ }^{31} \mathrm{~A}$ fin de cuentas viene a ser lo mismo que exigen los tratadistas; saber hablar en latín significa, implica, ser gramático. ${ }^{32}$

30 Véanse, por ejemplo, los sínodos de Cuéllar (Segovia) en 1325 (SH VI.); de Oviedo en 1382, c. 2 (SH III. 439-440); de Tuy en 1471-1487, c. 47 (SH I. 375-376); de Aguilafuente (Segovia) en 1472, c. 4 (SH VI.); de Braga en 1477. c. 27 (SH II. 100-101); de Porto en 1496, c. 9 (SH II. 361) = Braga en 1505, c. 8 (SH II. 146147); de Burgos en 1411, título De Summa Trinitate (edición de N. López Martínez, «Sínodos burgaleses del siglo XV», Burgense, 7 [1966] 241).

Los legados papales Juan de Abbeville (en 1228-1232) para los reinos hispanos y Guillermo Peyre Godin (en 1322) para el reino de Castilla, a la vez que constatan la situación poco halagüeña del clero español y castellano, tratan de aplicar a las iglesias hispanas las disposiciones de los concilios lateranenses III y IV en los concilios legatinos de Valladolid de 1228 y 1322. y de Lérida de 1229 (J.Tejada y Ramiro, Colección de cánones y de todos los concilios de la Iglesia española, III [Madrid 1851] 325, 487, 198-499; T. Noguer i Musqueras-J.M. Pons Guri, «Constitucions sinodals de Girona de la primera compilació», Anales del Instituto de Estudios Gerundenses, 18 [1966-1967] 64-65).

En cuanto a la interpretación de las denuncias de ignorancia clerical contenidas en los sínodos, remito a lo indicado antes en la nota 10.

31 Es la consigna legatina, tanto en 1228-1229 para todos los reinos hispanos como en 1322 para CastillaLeón, que no se promueva a nadie «fasta que sepan fablar latin» (Valladolid, 1228), «quousque latinis verbis loqui sciant» (Lérida, 1229), «nisi saltem literaliter (alias latinaliter) sciat loqui» (Valladolid, 1322).

32 Lo indicado en la nota 24 sobre la equivalencia entre ser gramático y saber latín queda especialmente de manifiesto en los sínodos; el de Lisboa de 1248, c. 4 (SH II. 298), recoge esta equivalencia de manera literal y unívoca: «[...] gramaticam adiscere compellatur donec latinis verbis competenter loqui sciat»; casi igual el de Avila de 1481, c. 2.1.1 (SH VI. 75): «[...] que no sabe cantar ni construyr ni fablar por gramatica la lengua latina». 
Esta primera exigencia corresponde a la función sacral, ad Deum, del clérigo: rezo de las horas canónicas, celebración de la misa; y, al mismo tiempo, es la base para cualquier saber ulterior.

En segundo lugar, por razón de su oficio ad hominem, se le exige saber la doctrina cristiana. No se le exige un conocimiento en profundidad, sino elemental, que le permita desarrollar bien su doble función de pastor (administración de los sacramentos) y de maestro (enseñanza-predicación de la doctrina cristiana).

En los sínodos de la provincia eclesiástica tarraconense se incluyen ambos tipos de saberes ya desde el concilio legatino de 1229 , celebrado en Lérida; incluso con atención preferente a la acción pastoral ad hominem de los curados, a los que se dota de directorios sacramentales para el buen desempeño del oficio: la Summa septem sacramentorum, promulgada por Pedro de Albalat en el sínodo de Barcelona de 1241 (sede vacante) y que se difundió con rapidez por varias diócesis, el Tractatus sacramentorum de Ramón Despont, publicado en el sínodo de Valencia de 1296, el resumen doctrinal que, a modo de manual, incluye el sínodo de Lérida de 1301, y la normativa de marcado acento pastoral de los sínodos de Gerona (de fecha incierta entre 1247 y 1253) y de Barbastro (en la diócesis de Huesca-Jaca) de 1280, son ejemplos convincentes.

En los sínodos de las diócesis de Castilla y León, así como de Portugal, esta preocupación pastoral es más tardía. Hasta el concilio legatino de Valladolid de 1322 se ocupan, ante todo, de la ciencia clerical en su vertiente ad Deum: que sepan latín para rezar, celebrar y administrar los sacramentos sin error; apenas se alude a saber la doctrina para enseñarla. ${ }^{33}$ Después de 1322, y sobre todo en el siglo XV, la preocupación principal de los sínodos, cuando se ocupan de la ciencia clerical, se centra muy especialmente, cuando no exclusivamente, en los curados, y se concreta, no sólo en saber latín, sino particularmente en saber bien, de memoria, la doctrina cristiana. Con este motivo, se les facilita un cuaderno con los elementos esenciales de la doctrina cristiana, que deben aprender para, a su vez, enseñarla a los parroquianos..$^{3+}$

Fuera de estas referencias especiales a los curados, algunos sínodos precisan también los saberes clericales conforme al grado de clericatura, distinguiendo las órdenes mayores o sagradas de las órdenes menores ${ }^{35} \mathrm{y}$, dentro de las mayores, el subdiaconado del

33 Lisboa, 1248, c. 4 (SH II. 298); Badajoz, 1255, c. 6 (SH V. 13 [indirectamente]; Braga, 1281, c. 1, 2 y 4 (SH II. 11-12); Santiago de Compostela, 1289, c. 12 (SH I. 275) [indirectamente]; León, 1303, c. 13 y 39 (SH III. 266 y 281).

34 Toledo, 1323, c. 5 (edición de José Sánchez Herrero, Concilios Provinciales y Sínodos Toledanos de los siglos XIV y XV, La laguna: 1976, p. 174): ofrece a sus curados una instrucción breve de la doctrina, que deberán tener, en romance y en latín, para instruir por ella a los fieles; Segovia 1325 (SH VI. 261-369) promulga un amplio Libro sinodal en romance para uso de los clérigos y: en especial, de los curados. La atención preferente al clérigo curado es común a todos; véanse, por ejemplo, Lisboa, 1403, c. 2 (SH II. 320); Valença do Minho, 1444, c. 4 (SH II. 427); Segovia, 1472, c. 4 (SH VI. 441-444); Avila; 1481, c. 2.1.1 (SH VI. 75-77).

35 Por ejemplo, Zaragoza 1338, c. 1 (edición de J.M. Ochoa Martínez de Soria, «Los dos sínodos de Zaragoza bajo el pontificado de D. Pedro Lz. de Luna...», Scriptorium Victoriense, 2 [1955] 151), para admitir a la tonsura exige saber bien leer y cantar; y en la constitución segunda (Ochoa, 152), para admitir a las órdenes sagradas exige que los candidatos sepan bien leer y gramática. 
sacerdocio $^{36}$. También se alude, en general, a que todos los clérigos deben ser letrados y conocer el oficio que corresponde a cada uno $0^{37}$.

Las referencias a los centros escolares donde los clérigos podían, o debían, estudiar, ni son frecuentes ni nos aclaran si en realidad existían en todas las diócesis, conforme a las normas lateranenses y legatinas. En algunos se hace referencia genérica a estudios generales o especiales o, simplemente, al privilegio de dispensa de residencia en el beneficio que se concede a quien va a estudiar. ${ }^{38}$

Un aspecto en el que se insiste en muchos sínodos es en el examen de los candidatos a órdenes, especialmente sagradas; y en el examen de los clérigos en general y de los curados en especial que deben realizar los arcedianos en sus visitas pastorales a sus respectivos arcedianatos. ${ }^{39}$ La materia principal del examen es la gramática; en ella se resume la exigencia de saberes de los clérigos.

Un ejemplo revelador en este sentido es el de la diócesis de Santiago de Compostela en tiempos del obispo Lope de Mendoza (1399-1445). En el sínodo de 1435 se lamenta el obispo de la escasez de clérigos curados; esta falta se debía a la pobreza de los clérigos candidatos, que no podían costearse los estudios de gramática y, consecuentemente, no eran promovidos a las órdenes sagradas y a los beneficios curados; así pues, los que fallecían no encontraban

36 Por ejemplo, Tuy, 1482, c. 12 (SH I. 357): «E antes que reçiban orden de epistola, sean examinados si saben bien leer e cantar y rezar las Horas canonicas. E antes que sean hordenados de horden sacerdotal, sean examinados primeramente sy saben rezar las Horas canonicas e regirlas por sy, e sy saben el ofiçio de bautizar e que lo lean despachadamente $[\ldots] »$.

37 Por ejemplo, Porto, 1496, c. 9 [= Braga 1505, c. 8] (SH II. 361 y 146): «[...] todollos clerigos, especialmente aos de missa que tem cura dalmas, que daqui em diante aprendam a leer, cantar e rezar como a seu officio som obrigados».

38 En el sínodo de Logroño (diócesis de Calahorra) de 1240, c. 31 (edición de F. Bujanda, «Documentos para la historia de la diócesis de Calahorra. Tres sínodos del siglo XIII», Berceo, 1 [1946] 124-125), se da libertad a los clérigos para ir a estudiar a escuelas generales, "así como a Bolonia, o a París, o a Tolosa, o a Calahorra». En el de Aguilafuente (Segovia) de 1472, c. 4 (SH VI. 441-444) se dispone que los clérigos ignorantes que estudien durante cuatro años en estudio general hasta que sepan «leer e construyr e la dicha gramatica e lengua latina, e, asimismo, cantar conpetentemente el canto llano». En el de Ávila de 1481, c. 2.1 .1 (SH VI. 75-77) se dispone prácticamente lo mismo que en el de Aguilafuente, pero en él se habla de «estudio general o especial».

39 Por ejemplo, Lisboa, 1248, c. 4 (SH II. 298); Valencia, 1258 (edición de J. Sáenz de Aguirre, Collectio maxima conciliorum Hispaniae et Novi Orbis V [Romae 1755] 200 n. 147); León 1267 o 1262, c. 52 (SH III. 248); León, 1303, c. 13 (SH III. 266); Zaragoza, 1338, c. 2 (Ochoa, 151-152); Barcelona, 1354, c. 38 y 130 (edición de J.N. Hillgarth y G. Silano, «A compilation of the diocesan synods of Barcelona (1354): critical edition and analysis», en Mediaeval Studies, 46 [1984] 109 y 153); Lisboa, 1403, c. 2 (SH II. 320); Santiago de Compostela, 1435, c. 1 (SH I. 323); Valença do Minho, 1444, c. 4 (SH II. 427); Aguilafuente (Segovia), 1472, c. 4 (SH VI. 441-444); Braga, 1477, c. 27 (SH II. 100-101); Toledo, 1480, c. [15] (Sánchez Herrero, 313); Ávila, 1481, c. 2.1.1 (SH VI. 75-77); Tuy, 1482, c. 12 (SH I. 357); Porto, 1496, c. 34 y 36 (SH II. 379-380 y $381-382)=$ Braga 1505 , c. 32 y 34 (SH II. 164 y 166); Badajoz, 1501, c. 5.1 y 6.1 (SH V. 56-57 y 58-59). 
fácilmente sustitutos. Para remediar la situación, el obispo decide rebajar el nivel de exigencia; ya no necesitarán ser gramáticos para ser promovidos, bastará «que sepan bien leer y cantar» ${ }^{\ddagger 0}$.

Del texto sinodal anotado se deducen dos conclusiones: primera, que el examen se practicaba con regularidad y seriedad en la diócesis compostelana, al menos, para la promoción a las órdenes sagradas; segunda (y ésta con toda evidencia), que saber gramática, ser gramático, significaba entonces algo más que saber bien leer y cantar.

José M. ${ }^{a}$ Soto Rábanos

CSIC, Estudios Históricos

Duque de Medinaceli, 6

E-28014 Madrid

40 C. 1 (SH I. 323): «Lo primero. Entre las otras cosas que se requiere para que los clerigos sean promovidos a ordees sacras, es neçesario al menos que sean gramatiquos; pero considerando nos, segundo nos fue fecha relaçion, que las iglesias curadas non son administradas nin regidas por defecto e mingoa de clerigos que falesçeron asy por mortaldades commo por cabsa que se non ordenaron por la pobresa para aprender gramatiqua, por ende querendo nos proveer sobrelo es nuestra merçede por la tal neçesidade que los clerigos que se quisieren ordenar que sepan bien leer e cantar [...] se presenten ante nos para que los mandemos sobrelo examinar e les demos liçençia para que se ordenen, en caso que non sepan gramatiqua». 